\title{
Influence of Double Entry Volute on Incidence Angle Variation Under Steady Flow: Numerical Investigation
}

\author{
Balamurugan A Gurunathan ${ }^{1}$, Uswah Khairuddin ${ }^{2,}{ }^{*}$, Nazrun Nabill Azlan Shah ${ }^{1}$, Ricardo Martinez- \\ Botas $^{3}$
}

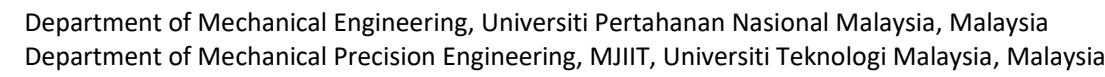

\section{Article history:}

Received 23 August 2020

Received in revised form 22 October 2020

Accepted 25 October 2020

Available online 31 October 2020

\section{Keywords:}

Turbochargers volute; symmetric volute; double entry volute; incidence angle
EGR extraction from one side of the exhaust manifold creates imbalance of mass flow in a double entry turbine. To overcome this problem, the asymmetric double entry turbine was introduced. The performance maps of this turbine were obtained through extensive test configurations in both steady and unsteady flow conditions at Imperial College cold flow test rig. Two main configurations were investigated; nozzleless and nozzle vane setting. Nevertheless, no attempt has been made to compare the performance of asymmetric double entry turbine to that of the symmetric counterpart. One way to make comparison between these two double entry turbine volutes, is by using numerical simulation. This is achieved by using ANSYS CFX tool in this paper. A symmetric double entry volute CAD model is developed using the same $A / R$ ratio as the asymmetric counterpart, adopting the same mixed flow rotor, inlet and exit ducts. The steady state numerical investigation was conducted at two turbine speeds, 30k RPM and 48k RPM, for the nozzleless configuration. Steady state experimental results of asymmetric double entry turbine are set as the boundary condition in the simulation. Validation of the simulation results with that of the experimental data, shows good agreements for both speed lines for the asymmetric double entry turbine. The symmetric double entry turbine recorded peak efficiencies; lower by $2.8 \%$ and $8 \%$, at $30 \mathrm{k}$ RPM and 48k RPM respectively, compared to that of asymmetric double entry turbine. The results of steady state conditions of the asymmetric double entry turbine suggest that the distribution of the incidence angle is better than the symmetric double entry turbine as it is able to maintain the incidence angle at off-design and design point operating condition within the same range.

Copyright $@ 2020$ PENERBIT AKADEMIA BARU - All rights reserved

\section{Introduction}

Diesel engines are widely in use worldwide as it provides high power with low fuel consumption and low $\mathrm{CO}_{2}$ emission. In diesel engines, the nitrogen oxides (NOx) emission which contributes

\footnotetext{
* Corresponding author.

E-mail address: uswah.kl@utm.my (Uswah Khairuddin)
} 
towards the major hazardous pollutants remain high [1]. The formation of $\mathrm{NO}_{\mathrm{x}}$ in diesel engines is such a complex mechanism as owing to heterogeneous and transient type of combustion nature in diesel engine [2]. One way of achieving reduction in $\mathrm{NO}_{x}$ by introducing $\mathrm{EGR}$ in which it recirculates part of exhaust gas to the combustion chamber [3-5]. However, EGR extraction from one side of the exhaust manifold creates imbalance of mass flow entering a turbocharger [5]. Twin and double entry turbine was introduced to overcome this problem and various study under steady and unsteady condition were conducted in this configuration [5-14].

Newton [10] experimented with a symmetric double entry turbine with a mixed flow turbine rotor ' $A$ ' which was designed in Imperial College London [15], and has shown that peak efficiency can be achieved up to $79.7 \%$ with nozzle setting in steady state condition. A year later, Martinez-Botas and Sakai [16] designed an asymmetric double entry turbine which they claim can improve flow balance around turbine wheel during high EGR rate and subsequently improved energy extraction capability. Gurunathan [17] then used this asymmetric turbine with the same mixed flow rotor ' $A$ ' with nozzleless setting and recorded $77 \%$ peak efficiency at 0.68 velocity ratio in both experiment and simulations. It is thought that with a nozzled setting, the performance might match or higher than achieved by Newton [10]. However, a direct comparison between the volutes is not suitable due to different volute shape used in the study of Gurunathan [17] and Newton [10]. Therefore, a conclusion for which volute design is better- asymmetric or symmetric; cannot be made.

In this paper, the asymmetric volute designed by Martinez-Botas [16] is modified to be symmetric while maintaining the shape and $A / R$ ratio. The new symmetric design will be analyzed using CFD simulations and compared with the asymmetric CFD simulation results which has already been validated against experimental measurements. Due to similar geometric specifications, a direct and fair comparison can be made and finally a decision on which design is more suitable for EGR exhaust gas characteristics, can be made.

\section{Methodology}

The design of the symmetric double entry turbine volute and the setup of simulation is the result of modification of asymmetric double entry turbine geometry from Gurunathan [17], considering Rotor ' $A$ ' specification designed by Abidat [18] in Imperial College London.

\section{$2.1 \mathrm{~A} / \mathrm{R}$ Ratio of Turbine}

The design will consider same A/R ratio of the turbine with different azimuth angle for each scroll. The corresponding value of $A / R$ ratio of each of the scroll for the asymmetric turbine volute is stated in the equation below [17]

$$
\begin{aligned}
& \left(\frac{A_{2}}{r_{2}}\right)_{i}=13.33 \mathrm{~mm} \\
& \left(\frac{A_{2}}{r_{2}}\right)_{0}=16.67 \mathrm{~mm}
\end{aligned}
$$

The relationship between A/R ratio with azimuth angle represented in the Figure 1. 


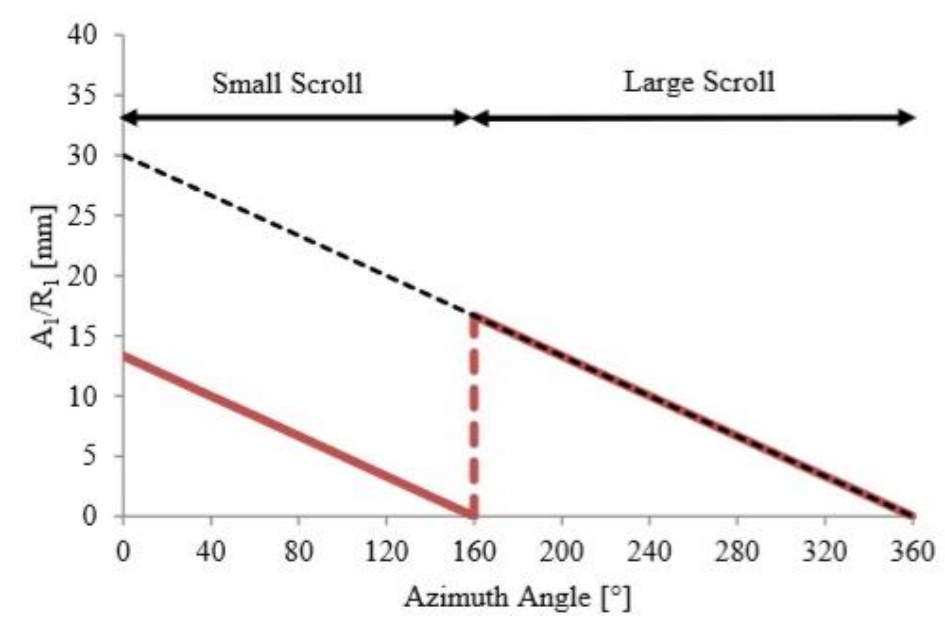

Fig. 1. Relationship between $A / R$ ratio with azimuth angle of asymmetric double entry turbine [17]

\subsection{Volute Cross Section Shape}

The flow of exhaust gas to the volute passage is influenced by the type of volute cross sectional shape. The right shape will contribute to the smooth flow of exhaust gas and there are a few volute shapes are used conventionally. Figure 2 shows the conventional volute design with different shapes. In this research, the volute shape $(\mathrm{I})$ is used.

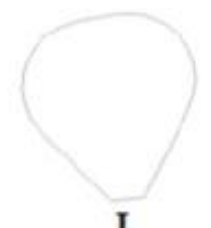

I

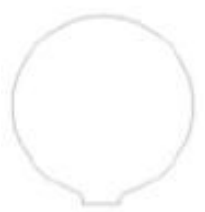

IV

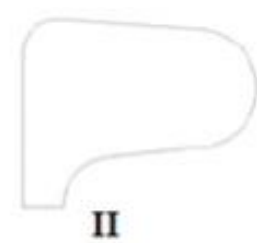

II

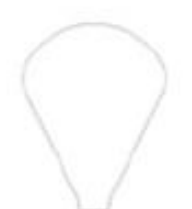

V
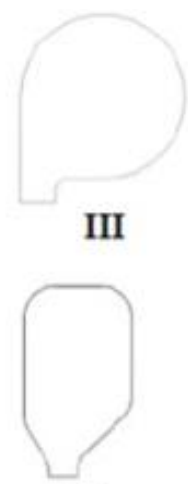

VI

Fig. 2. Conventional volute design with different shapes [16]

The area of cross section from asymmetric volute is used in the Eqs. (1) and (2). In asymmetric turbine volute design, Sakai [19] used $r_{\psi=0}=96.45 \mathrm{~mm}$ and and $A_{\psi=0}=1322.02 \mathrm{~mm}^{2}$ for small scroll. For the large scroll, the values are $r_{\psi=0}=101.32 \mathrm{~mm}$ and $A_{\psi=0}=1749.27 \mathrm{~mm}^{2}$. The symmetric radius is determined by forecasting the value of $A / R$ ratio with azimuth angle. Then, the values of radius are inserted back into the Eqs. (1) and (2) and the area of volute cross section are calculated with the values of $A / R$ which correspond to the new azimuth angle. The difference in $A / R$ between asymmetric and symmetric turbine volute are shown in Figure 3 . For the inner scroll, at $\psi=0^{\circ}$, both scrolls show same value of $A / R$ ratio of $13.33 \mathrm{~mm}$. As for the outer scroll, the value of $A / R$ ratio are $16.67 \mathrm{~mm}$ at $\psi=160^{\circ}$ for asymmetric volute at $\psi=180^{\circ}$ for symmetric volute. 
- Asymmetric inner scroll $\boldsymbol{a}$ Asymmetric outer scroll

$\Delta$ Symmetric inner scroll $\times$ Symmetric outer scroll

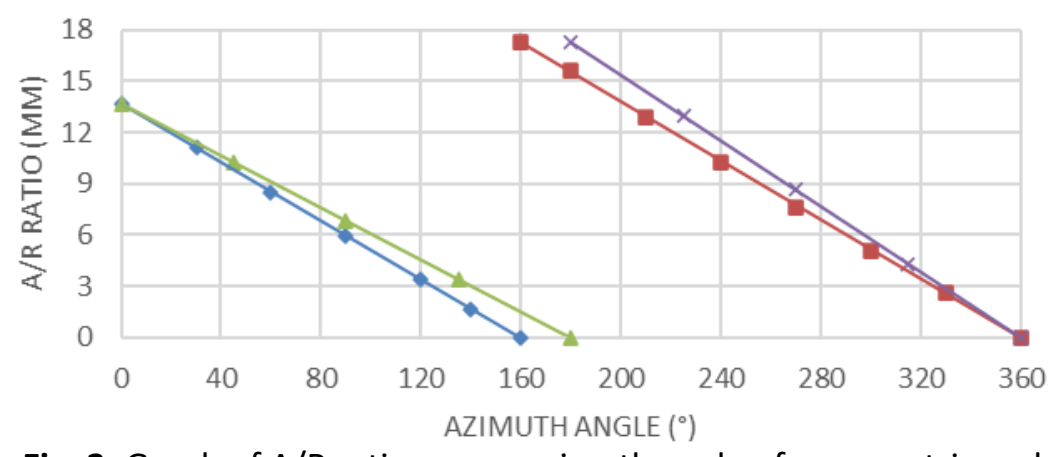

Fig. 3. Graph of $A / R$ ratio versus azimuth angle of asymmetric and symmetric volute

\subsection{D Volute Model}

A new 3D volute model is developed by using the new symmetric volute dimension in SolidWorks. As shown in Figure 4, the sketch for the area and radius are divided with 9 sections from $0^{\circ}$ to $360^{\circ}$. The difference between asymmetric and symmetric 3D model as shown in Figure 5.

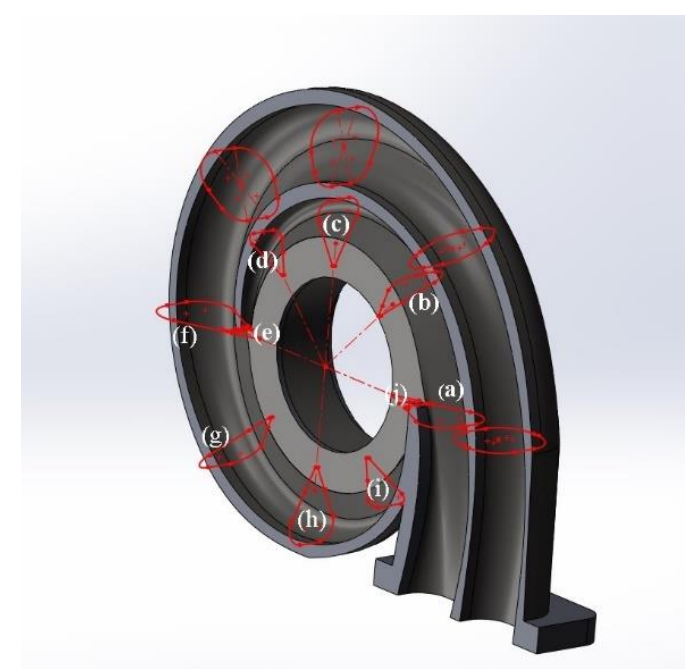

Fig. 4. Cross sections of symmetric volute in SolidWorks
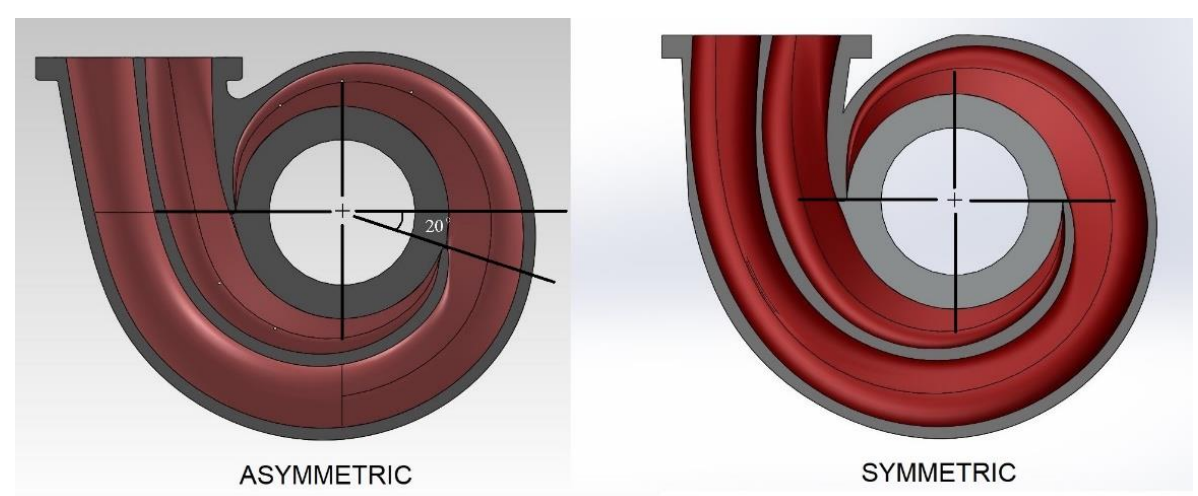

Fig. 5. Comparison of asymmetric and symmetric turbine 


\subsection{Computational Fluid Dynamics (CFD) Simulation for Symmetric Volute}

The simulation software used in this project is ANSYS CFX. There are 4 stages in this simulation which consist of preparation of CFD domains, Pre Processing, Solver and Post Processing. The domains consist of conversion inlet, symmetric turbine housing, rotor and outlet and the assembly of these domains are set same as the real assembly on the experimental rig. Figure 6 below show the 3D CAD models of the simulation.

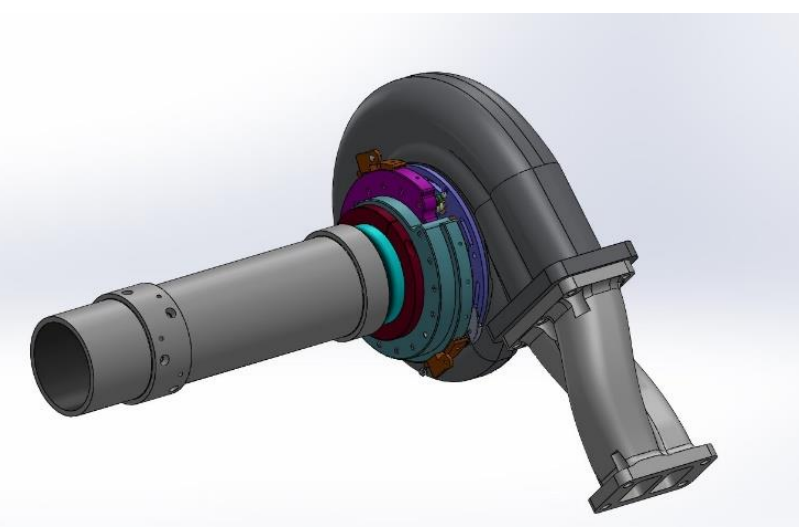

Fig. 6. Assembly of 3D models following the experiment arrangement

Every fluid domain is meshed using ANSYS Mesh Workbench except for the rotor. The rotor is meshed using the ANSYS Turbogrid in which the software is specific to mesh the rotor for turbomachinery case. The meshing and setup for the symmetric turbine is similar to that of asymmetric turbine. Table 1 shows the details of the meshing of the domains and Figure 7 shows the meshes of the fluid domains.

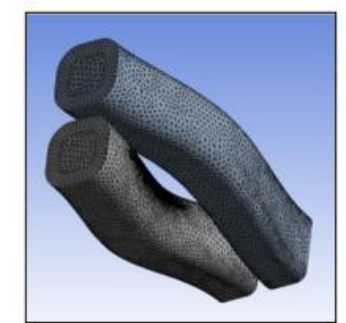

Mesh conversion of inlet

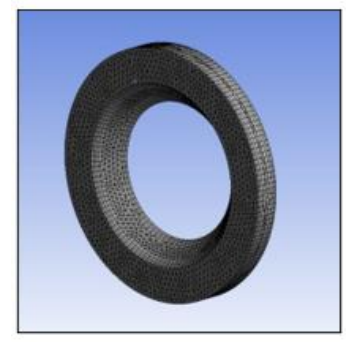

Mesh of vaneless

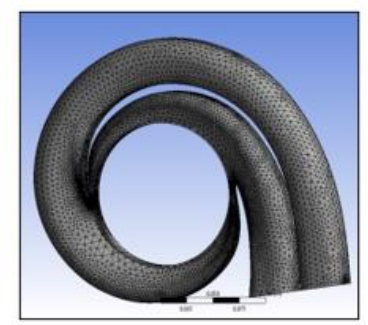

Mesh of symmetric volute

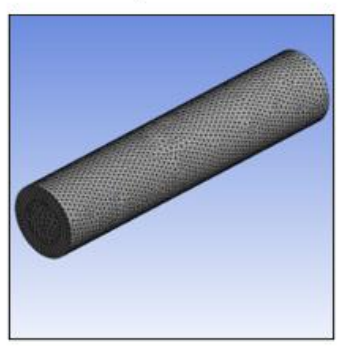

Mesh of outlet

Fig. 7. Mesh of the fluid domains

The equation of k-epsilon $(k-\varepsilon)$ turbulent model is used in this simulation. The prediction of turbulent flow to analyze turbocharger performance by using this turbulent model is accurate as mentioned by Palfreyman [20]. 
Table 1

Domain meshing parameters

\begin{tabular}{lll}
\hline Mesh preference & & \\
\hline Physics preference & CFD & \\
Solver preference & CFX & \\
Relevance center (mesh size) & Fine & \\
Type of mesh & Hexahedral, prism and pyramid \\
Turbine mesh near wall spec. & Y+ and Reynolds No 1.0e 6 \\
& \multicolumn{3}{l}{} \\
Domain details & \multicolumn{3}{l}{} \\
Type of mesh & Unstructured \\
Domain & Total nodes & Total elements \\
Conversion inlet & 65135 & 190325 \\
Symmetric volute & 185367 & 500829 \\
Vanesless & 131192 & 30740 \\
Outlet & 25323 & 70489 \\
Type of mesh & Structured & \\
Turbine A & 3072708 & 2817336 \\
\hline
\end{tabular}

\subsection{Computational Fluid Dynamics (CFD) Validation Exercise for Asymmetric Volute}

The purpose of this process is to determine how good the simulation model predicts the experimental result. In other words, the process is to ensure the simulation model has high degrees of agreement with the experimental data. The validation is conducted by running the simulation of asymmetric volute and the results are compared with that of the experimental measurements. The parameters from the asymmetric test which are mass flow rate, total to static efficiency, pressure ratio and velocity ratio are compared directly with the experimental data and results. The setup in the preprocessing and post processing remains the same, as explained previous, except for the volute domains. Table 2 shows the mesh details for the asymmetric volute domain.

\section{Table 2}

Asymmetric volute meshing parameters

\begin{tabular}{lll}
\hline Domain details & & \\
\hline Type of mesh & Unstructured & \\
Domain & Total nodes & Total elements \\
Asymmetric volute & 274931 & 742788 \\
\hline
\end{tabular}

\subsection{Performance Parameter}

Single entry turbine performance in steady state operations are defined by four standard dimensionless parameters, which are total to static isentropic efficiency, velocity ratio, mass flow parameter and pressure ratio. These parameters were adjusted to represent different flow conditions in each entry of a double entry turbine as in Eqs. (3) to (9). Subscript i and o have been defined for the inner and outer volute respectively.

$$
\begin{aligned}
& \eta_{t s}=\frac{\left(\frac{\tau 2 \pi N}{60}\right)}{\dot{m}_{i} C_{p}\left(T_{01}\right)_{i}\left[1-\left(\frac{P_{5}}{P_{01}}\right)_{i}^{\frac{\gamma-1}{\gamma}}\right]+\dot{m}_{0} C_{p}\left(T_{01}\right)_{o}\left[1-\left(\frac{P_{5}}{P_{01}}\right)_{o}^{\frac{\gamma-1}{\gamma}}\right]} \\
& M F P=\frac{\left(m_{1}+m_{0}\right) \sqrt{T_{01}}}{P_{01}}
\end{aligned}
$$


$\mathrm{VR}=\frac{\mathrm{U}_{2}}{\mathrm{C}_{\mathrm{is}}}=\frac{\pi \mathrm{D}_{4}\left(\frac{\mathrm{N}}{60}\right)}{\sqrt{\left(\frac{\left(\mathrm{W}_{1 \mathrm{~s}}\right)_{\mathrm{i}}+\left(\mathrm{w}_{1 \mathrm{~s}}\right)_{\mathrm{o}}}{\mathrm{m}_{\mathrm{i}}+\mathrm{m}_{\mathrm{o}}}\right)}}$

$P R=\frac{P_{i}\left(\dot{W}_{1 s}\right)_{i}+P R_{o}\left(\dot{W}_{1 S}\right)_{0}}{\left(\dot{W}_{1 S}\right)_{i}+\left(\dot{W}_{1 S}\right)_{o}}$

$\mathrm{T}_{01}=\frac{\dot{\mathrm{m}}_{1}\left(\mathrm{~T}_{01}\right)_{\mathrm{i}}+\mathrm{m}_{\mathrm{o}}\left(\mathrm{T}_{01}\right)_{\mathrm{o}}}{\mathrm{m}_{1}+\mathrm{m}_{\mathrm{o}}}$

$\mathrm{P}_{01}=\frac{\left(\mathrm{P}_{01}\right)_{\mathrm{i}}\left(\dot{\mathrm{W}}_{1 \mathrm{~s}}\right)_{\mathrm{i}}+\left(\mathrm{P}_{01}\right)_{\mathrm{o}}\left(\dot{\mathrm{W}}_{1 \mathrm{~s}}\right)_{\mathrm{o}}}{\left(\dot{\mathrm{W}}_{1 \mathrm{~s}}\right)_{\mathrm{i}}+\left(\dot{\mathrm{W}}_{1 \mathrm{~s}}\right)_{\mathrm{o}}}$

$\mathrm{W}_{\mathrm{is}}=\dot{\mathrm{m}} \mathrm{C}_{\mathrm{p}} \mathrm{T}_{01}\left[1-\left(\frac{\mathrm{P}_{5}}{\mathrm{P}_{01}}\right)^{\frac{\gamma-1}{\gamma}}\right]$

\subsection{Boundary Conditions}

The data for inlet and outlet boundary condition are experimental points obtained from vaneless asymmetric volute testing in equal admission steady condition. Gurunathan [17] tested extensively the asymmetric double entry turbine in a cold flow condition at Imperial College test rig using an eddy current dynamometer. The equal admission steady flow testing was carried out at two different speeds; 30k RPM and 48k RPM. In this boundary condition setup, 30k RPM resembles of $50 \%$ of the turbine speed and 48k RPM speed resembles of $80 \%$ of the turbine speed. The experimental points are shown in Table 3 and 4.

\section{Table 3}

Boundary conditions at 30k RPM

\begin{tabular}{lllllll}
\hline Point & $\left(\mathrm{P}_{01}\right)_{\mathrm{i}}(\mathrm{Pa})$ & $\left(\mathrm{P}_{01}\right)_{\circ}(\mathrm{Pa})$ & $\left(\mathrm{T}_{01}\right)_{\mathrm{i}}(\mathrm{K})$ & $\left(\mathrm{T}_{01}\right)_{\circ}(\mathrm{K})$ & $\mathrm{P}_{\text {exit }}(\mathrm{Pa})$ & Rotor Speed $(\mathrm{RPM})$ \\
\hline 1 & 162733.40 & 162800.75 & 338.44 & 337.65 & 100009.08 & 30049.39 \\
2 & 133144.36 & 132947.61 & 332.74 & 332.47 & 100097.76 & 30420.15 \\
3 & 123634.21 & 123587.46 & 334.54 & 334.39 & 100069.40 & 29323.30 \\
4 & 116257.02 & 116373.73 & 332.89 & 332.59 & 99980.24 & 29901.19 \\
5 & 112004.49 & 111510.55 & 332.13 & 331.68 & 100078.11 & 29838.86 \\
\hline
\end{tabular}

\section{Table 4}

Boundary conditions at 48k RPM

\begin{tabular}{lllllll}
\hline Point & $\left(\mathrm{P}_{01}\right)_{\mathrm{i}}(\mathrm{Pa})$ & $\left(\mathrm{P}_{01}\right)_{\circ}(\mathrm{Pa})$ & $\left(\mathrm{T}_{01}\right)_{\mathrm{i}}(\mathrm{K})$ & $\left(\mathrm{T}_{01}\right)_{\circ}(\mathrm{K})$ & $\mathrm{P}_{\text {exit }}(\mathrm{Pa})$ & Rotor Speed $(\mathrm{RPM})$ \\
\hline 1 & 185527.03 & 184903.18 & 334.79 & 334.49 & 100122.90 & 48615.65 \\
2 & 159079.33 & 158589.43 & 331.41 & 331.00 & 100074.01 & 46865.62 \\
3 & 144041.93 & 143795.04 & 331.75 & 331.18 & 100076.25 & 48411.42 \\
4 & 137844.65 & 138110.36 & 336.70 & 336.39 & 100047.64 & 47799.20 \\
5 & 127505.78 & 127444.23 & 333.68 & 333.38 & 100048.64 & 48027.87 \\
6 & 123801.42 & 123799.99 & 332.26 & 332.06 & 100068.33 & 47639.42 \\
\hline
\end{tabular}

\section{Results}

The simulation results of symmetric turbine volute are compared directly with simulation results of asymmetric turbine volute. Prior to this comparison, the validation exercise was carried to ensure simulation model is reliable in predicting the performance of the symmetric turbine. 


\subsection{Validation Results}

The simulation results of asymmetric turbine volute are compared directly with that of the experimental results obtained at Imperial College test rig. The overall mass flow parameter at $30 \mathrm{k}$ RPM is shown in Figure 8. It can be observed that the simulation curve follow experiment curve with overall Root Mean Square of the deviation is $5 \%$. The difference between experiment and simulation results at 30k RPM speed is shown in Table 5.

Figure 9 shows the total to static efficiency at 30k RPM under the same axis. It can be seen that the simulation demonstrated lower efficiency curve compared to experimental curve. From Table 6, the average percentage difference between results is $5.25 \%$ and the lowest percentage difference recorded at 0.44 velocity ratio with $2.87 \%$ efficiency.

Figure 10 shows the overall mass flow parameter at 48k RPM. The simulation curve shows the mass flow parameter follows experiment curve with lower value. The overall percentage difference recorded between curves are $4.61 \%$. From Table 7, it can be concluded that experiment has higher mass flow parameter in overall compared to simulation result.

Figure 11 shows the total to static efficiency at 48k RPM plotted at the same axis. From the figure, it can be observed that the simulation total to static efficiency are lower than experiment. In overall, the simulation curve demonstrated same trend with experiment curve but with average percentage difference of $8.92 \%$. The difference between experiment and simulation results at 48k RPM speed is shown in Table 8.

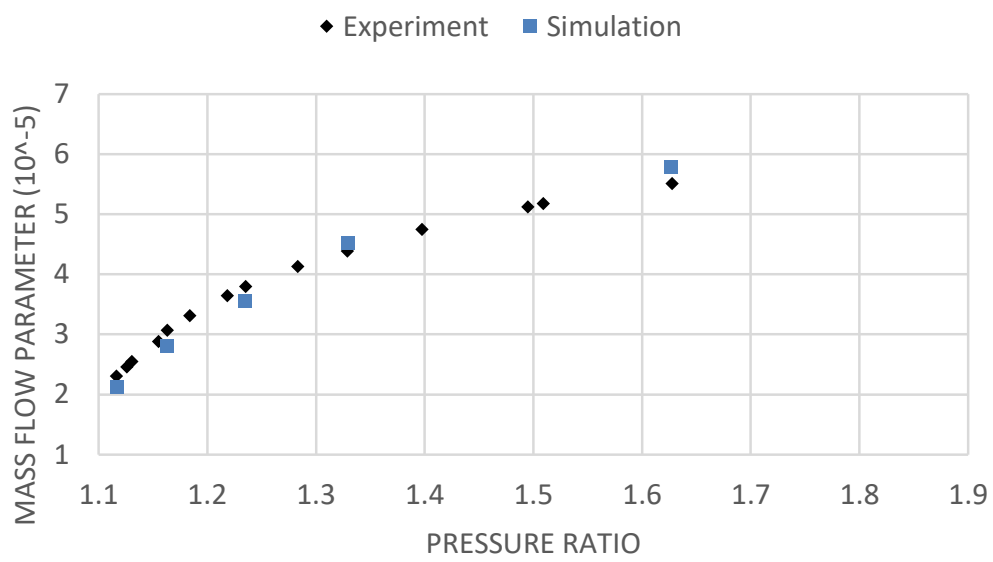

Fig. 8. Experiment vs Simulation Overall mass flow parameter at 30k RPM

Table 5

Overall Mass flow parameter comparison at 30k RPM

\begin{tabular}{llll}
\hline Pressure ratio & \multicolumn{2}{l}{ Overall Mass flow parameter MFP $\left(\times 10^{-5}\right)$} & \multirow{2}{*}{ \% Difference } \\
\cline { 2 - 3 } & Experiment & Simulation & \\
\hline 1.12 & 2.30 & 2.12 & 1.12 \\
1.16 & 3.07 & 2.81 & 1.16 \\
1.24 & 3.80 & 3.55 & 1.24 \\
1.33 & 4.39 & 4.52 & 1.33 \\
1.63 & 5.51 & 5.78 & 1.63 \\
\hline
\end{tabular}




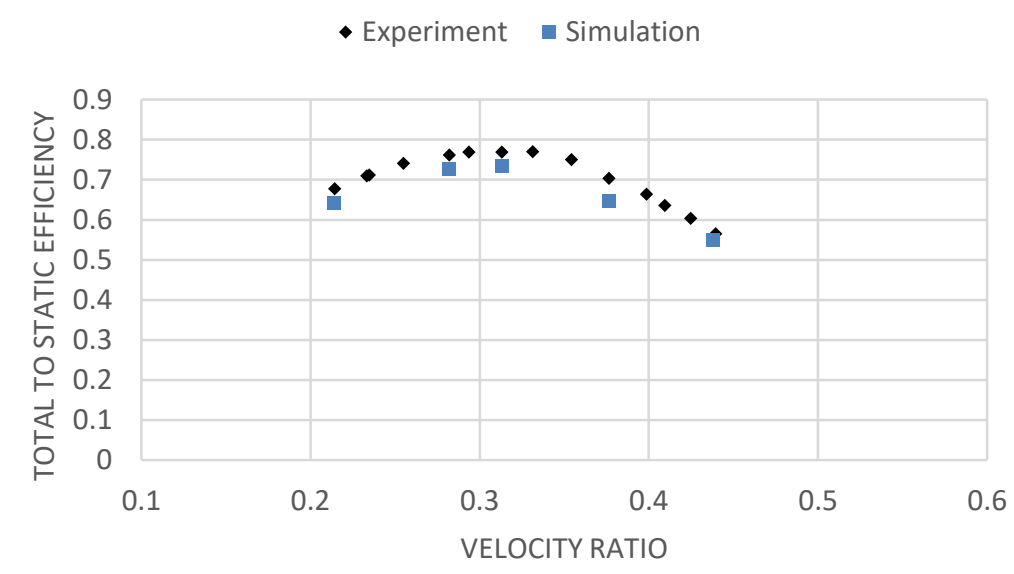

Fig. 9. Experiment vs Simulation Total to static efficiency at 30k RPM

Table 6

Total to static efficiency comparison at 30k RPM

\begin{tabular}{llll}
\hline \multirow{2}{*}{ Velocity ratio } & \multicolumn{2}{l}{ Overall Total to static efficiency (\%) } & \multirow{2}{*}{ \% Difference } \\
\cline { 2 - 3 } & Experiment & Simulation & \\
\hline 0.21 & 67.8 & 64.2 & 0.21 \\
0.28 & 76.2 & 72.8 & 0.28 \\
0.31 & 77.0 & 73.2 & 0.31 \\
0.38 & 70.1 & 64.5 & 0.38 \\
0.44 & 56.6 & 55.0 & 0.44 \\
\hline
\end{tabular}

- Experiment - Simulation

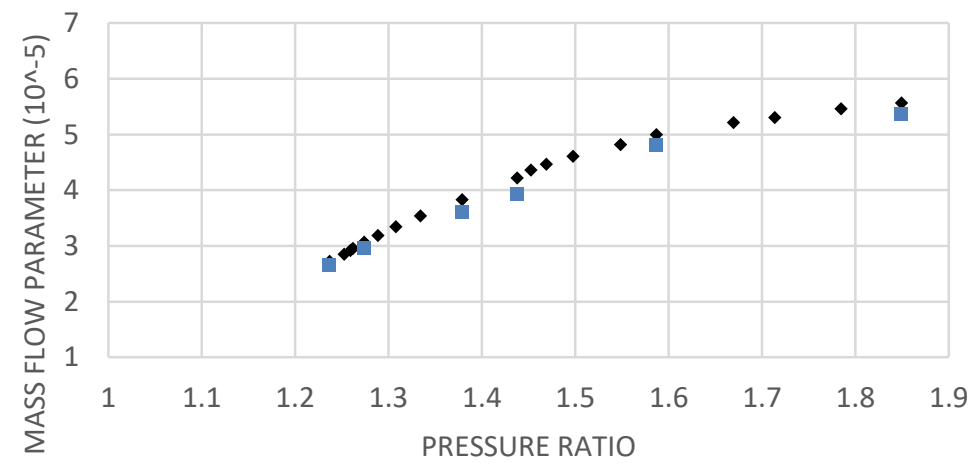

Fig. 10. Experiment vs Simulation Overall mass flow parameter at $48 \mathrm{k}$ RPM

Table 7

Overall Mass flow parameter comparison at 48k RPM

\begin{tabular}{llll}
\hline \multirow{2}{*}{ Pressure ratio } & \multicolumn{2}{l}{ Overall Mass flow parameter MFP $\left(\times 10^{-5}\right)$} & \\
\cline { 2 - 3 } & Experiment & Simulation & \\
\hline 1.24 & 2.73 & 2.65 & 1.24 \\
1.27 & 3.06 & 2.95 & 1.27 \\
1.38 & 3.83 & 3.61 & 1.38 \\
1.44 & 4.22 & 3.92 & 1.44 \\
1.58 & 5.00 & 4.80 & 1.58 \\
1.85 & 5.57 & 5.37 & 3.66 \\
\hline
\end{tabular}




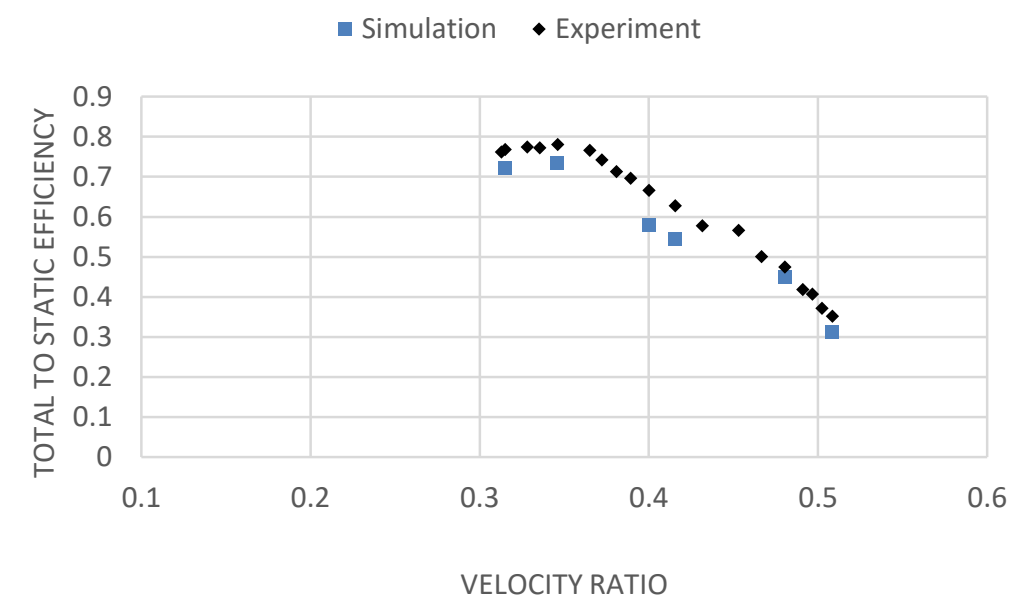

Fig. 11. Experiment vs Simulation Total to static efficiency at 48k RPM

Table 8

Total to static efficiency comparison at 48k RPM

\begin{tabular}{llll}
\hline \multirow{2}{*}{ Velocity ratio } & \multicolumn{2}{l}{ Overall Total to static efficiency (\%) } & \multirow{2}{*}{ \% Difference } \\
\cline { 2 - 3 } & Experiment & Simulation & \\
\hline 0.31 & 76.2 & 72.1 & 0.31 \\
0.35 & 78.1 & 73.3 & 0.35 \\
0.40 & 66.7 & 58.0 & 0.40 \\
0.42 & 62.7 & 54.5 & 0.42 \\
0.48 & 48.1 & 47.5 & 0.48 \\
0.51 & 35.2 & 31.1 & 0.51 \\
\hline
\end{tabular}

Based on the validation results, the average percentage difference for mass flow parameter and total to static efficiency in overall are below than $10 \%$ and it is acceptable to run the symmetric turbine volute with the same boundary condition and simulation used in validation tests.

\subsection{Performance Comparison at 30K RPM}

Figure 12 shows overall mass flow parameter of asymmetric and symmetric volute at 30k RPM. At pressure ratio below 1.2, both volutes show negligible difference of mass flow parameter. As the pressure increases, the symmetric demonstrated lower trend of mass flow parameter. The highest mass flow parameter recorded is $5.78 \times 10^{-5}\left(\mathrm{kgs}^{-1} \cdot \sqrt{\mathrm{K}}\right) / \mathrm{Pa}$ of asymmetric volute. The overall percentage difference between both volutes is $8.21 \%$. Table 7 shows the overall mass flow parameter between asymmetric and symmetric at 30k RPM. In overall, the asymmetric has higher mass flow parameter compared symmetric with highest percentage difference of $18.09 \%$ at 1.33 pressure ratio.

The total to static efficiency of asymmetric and symmetric turbine volute are compared at this operating speed. Figure 13 shows the plot of total to static efficiency of asymmetric and symmetric volute at 30k RPM operating speed. The efficiencies are observed in the range of 0.2 to 0.45 . Both volutes have demonstrated the increase in efficiency from 0.2 to 0.35 velocity and the efficiency decreases as the velocity ratio increases. From the figure, the symmetric curve shows same trend of asymmetric curve. Below 0.3 velocity ratio, significant difference in efficiency recorded. The peak efficiencies of asymmetric and symmetric volute are $73.2 \%$ and $71.2 \%$. The symmetric volute shows higher efficiency at 0.37 velocity ratio with $65.6 \%$ compared to asymmetric volute with $64.5 \%$. The 
lowest efficiency recorded is $53.6 \%$ for symmetric volute at 0.44 velocity ratio. The average percentage difference between volutes is $6 \%$.

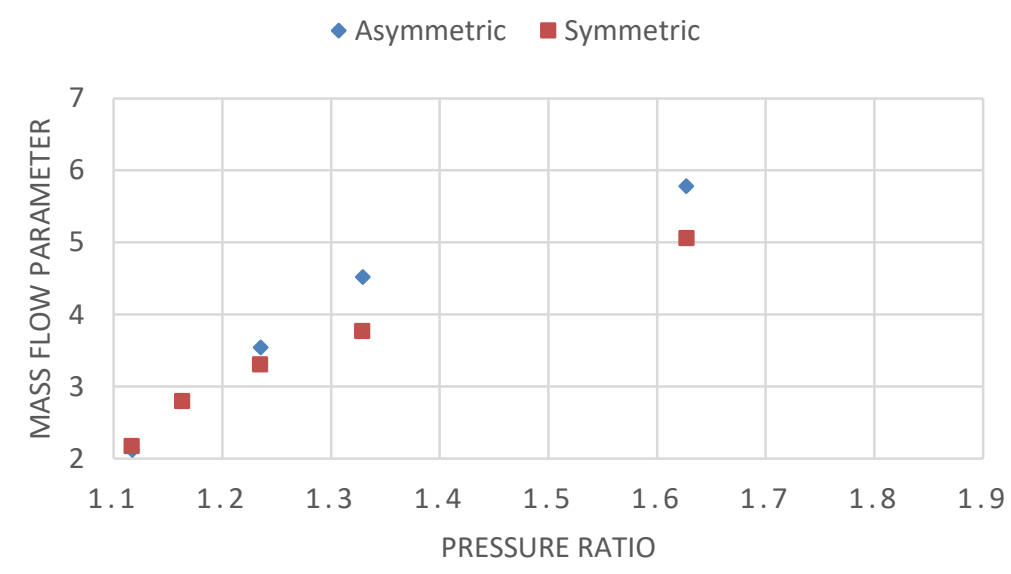

Fig. 12. Overall mass flow parameter at 30k RPM

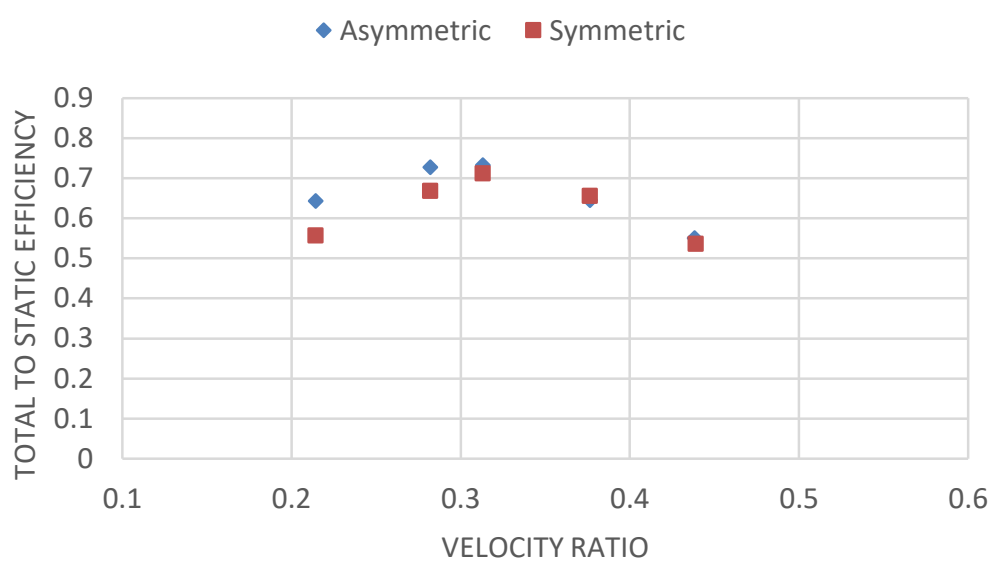

Fig. 13. Total to static efficiency at 30k RPM

\subsection{Performance Comparison at 48K RPM}

Figure 14 presents the overall mass flow parameter at 48k RPM. It can be seen the symmetric curve has same trend of asymmetric. Based on observation, pressure ratio below 1.4 shows negligible difference of mass flow parameter between the volutes. At 1.43 pressure ratio, the symmetric mass flow parameter shows slightly higher than asymmetric. However, asymmetric volute overcomes symmetric at the pressure 1.59 pressure ratio value of mass flow parameter, $4.80 \times$ $10^{-5}\left(\mathrm{kgs}^{-1} \cdot \sqrt{\mathrm{K}}\right) / \mathrm{Pa}$. The average percentage difference of overall mass flow parameter between asymmetric and symmetric is $3.06 \%$. The highest percentage difference is $6.45 \%$ at 1.59 pressure ratio. 


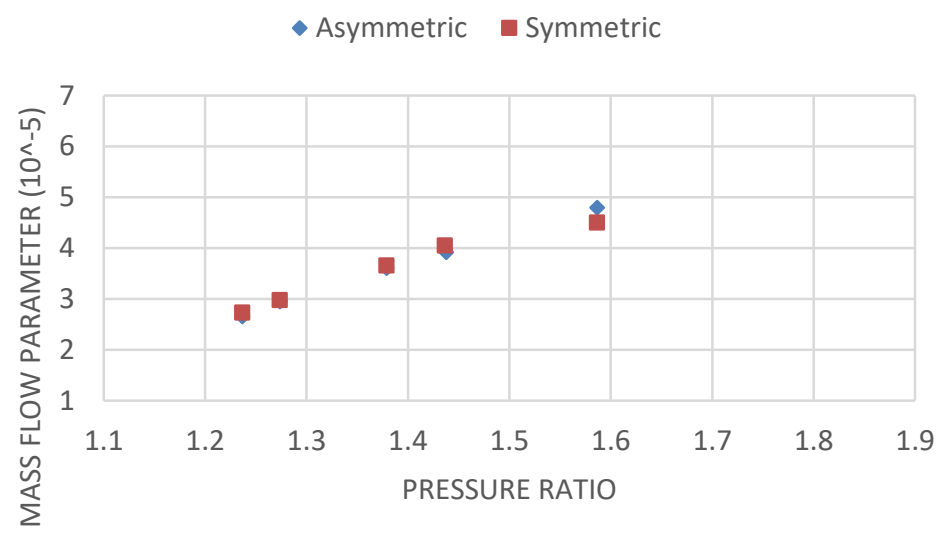

Fig. 14. Overall mass flow parameter at 30k RPM

Figure 15 shows the graph total to static efficiency of asymmetric and symmetric volute at $48 \mathrm{k}$ RPM. The velocity ratio observed in between 0.3 to 0.55 . It can be observed both volutes have the same trend but consistent difference in efficiency. Based on observation, the efficiency decreases as the velocity ratio increases for both volutes. From the plot, it can be seen the asymmetric volute has higher total to static efficiency compared to symmetric volute. The peak efficiency recorded from both volutes at 0.34 velocity ratio with $73.3 \%$ for asymmetric and $67.7 \%$ for symmetric. At the highest velocity of 0.51 , both volutes show similar decrease in efficiency. The average percentage different for both volutes is $8.43 \%$. Table 8 shows the total to static efficiency of asymmetric and symmetric volutes. The highest percentage difference recorded is $12.01 \%$ at 0.48 velocity and the lowest percentage difference recorded is $5.86 \%$ at 0.40 velocity ratio.

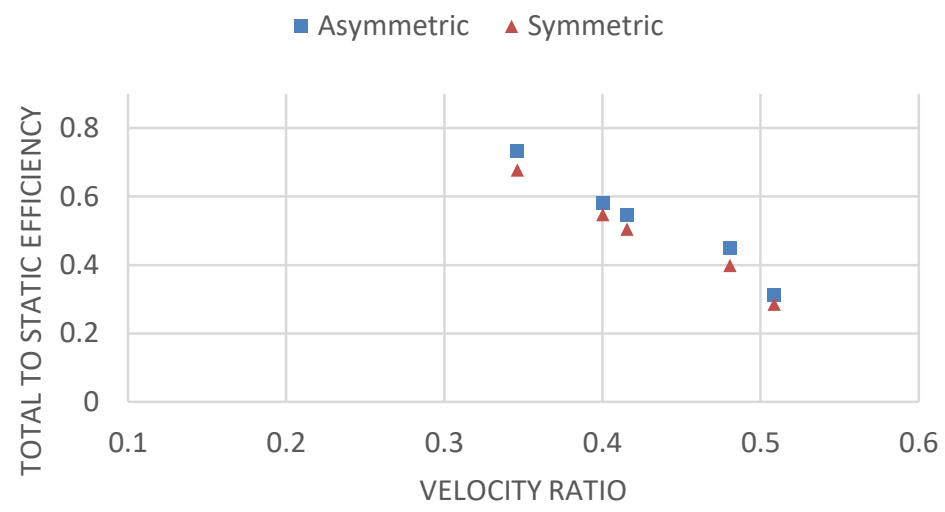

Fig. 15. Total to static efficiency at 30k RPM

\subsection{Flow Performance Analysis}

The flow performance was analyzed by comparing the incidence angle between the volutes. The incidence angle is referring to the difference between rotor inlet flow angle and blade angle at the rotor leading edge. As mentioned by Japikse and Baines [21], the optimum incidence angle for radial turbine in range of $-20^{\circ}$ to $-40^{\circ}$. The closer the incidence angle of the flow approaching to the optimum incidence angle range, the higher the turbine efficiency.

Figure 16 shows the incidence angle of asymmetric and symmetric volute plotted on the azimuth angle. In asymmetric volute, the lowest magnitude of incidence angle approached to optimum incidence angle is $-12.4^{\circ}$. It can be seen that in inner scroll asymmetric volute, the incidence angles 
are lower below $\psi=40^{\circ}$ and slightly increase and maintained until $\psi=160^{\circ}$. The incidence angles are observed and recorded lower as approach to $\psi=200^{\circ}$ and remained in constant magnitude. It also observed that the incidence angle increases as approached to tongue area from $\psi=320^{\circ}$. For symmetric volute, $-11.4^{\circ}$ is the lowest magnitude of incidence angle to approach the optimum angle. The inner scroll from $\psi=0^{\circ}$, the incidence angles are constant and slightly decreases at $\psi=150^{\circ}$. The outer scroll shows lower incidence angle recorded and the lowest incidence angle are observed at $\psi=330^{\circ}$. From the Figure 11 , the incidence angle of asymmetric volute approached closer to optimum incidence angle of $-20^{\circ}$ with difference of $7.6^{\circ}$ compared to symmetric volute with difference of $8.6^{\circ}$.

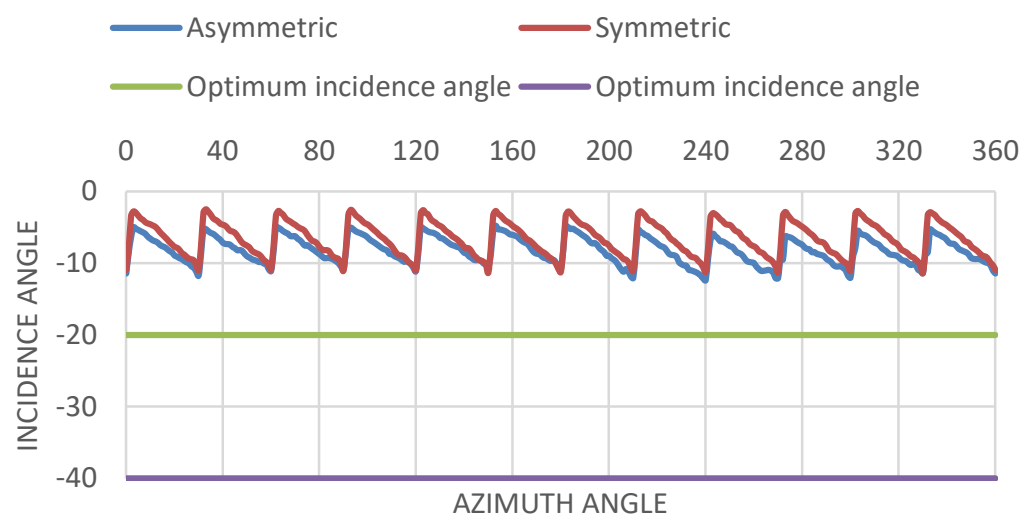

Fig. 16. Incidence angle comparison at 30k RPM

Figure 17 shows the incidence angle at 48k RPM. The lowest incidence angle recorded for asymmetric volute is $-9.63^{\circ}$. As for the symmetric volute, the lowest incidence angle recorded is $8.62^{\circ}$. The asymmetric volute shows constant low incidence angle at inner scroll correspond to $\psi=0^{\circ}$ to $\psi=160^{\circ}$. The incidence angle started to slightly lower as approached to $\psi=180^{\circ}$ and remained at the same magnitude in which refer to the flow in outer scroll. As for symmetric volute, the incidence angles are higher than asymmetric in overall. At $\psi=180^{\circ}$, the difference of incidence angle recorded between asymmetric and symmetric is $1^{\circ}$. For outer scroll, the magnitude of incidence angles are same at $\psi=300^{\circ}$ and $330^{\circ}$. From observation, clearly asymmetric volute also has higher efficiency as the incidence angle approaches closer to the optimum incidence angle of $-20^{\circ}$ with difference angle of $10.37^{\circ}$. The symmetric volute shows lower efficiency with difference in angle of $11.38^{\circ}$.

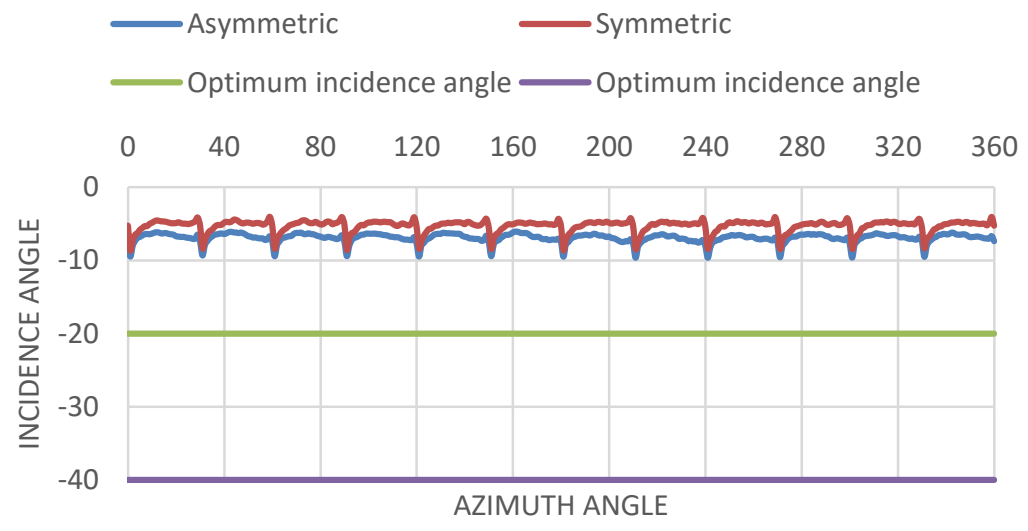

Fig. 17. Incidence angle comparison at 48k RPM 


\section{Conclusions}

An asymmetric volute design is said to improve flow balance from high EGR rate around turbine wheel and improve overall turbine energy extraction capability. Both experimental tests and CFD simulations shows that a nozzleless asymmetric turbine (nozzleless) with mixed flow rotor ' $A$ ' designed in Imperial college London is able to reach $77 \%$ peak efficiency at 0.68 velocity ratio. $A$ similar specification volute was designed but with symmetric configuration in order to compare the performance of turbines in asymmetric and symmetric configurations. The comparison was made using CFD simulations under steady conditions at $30 \mathrm{~K}$ RPM and $48 \mathrm{~K}$ RPM to reflect $50 \%$ and $80 \%$ turbine speed respectively.

Comparison of CFD simulations shows that the symmetric volute design achieved lower total to static efficiency compared to asymmetric volute with $2.77 \%$ and $8 \%$ lower efficiencies at peak efficiency for 30K RPM and 48K RPM respectively. Further analysis on incidence angles shows that magnitude of incidence angle for asymmetric volute is closer to the optimum incidence angle of $-20^{\circ}$ and the incidence angle for symmetric volute is closer to the positive range. Therefore, asymmetric volute design is more optimum for EGR exhaust gas operations.

This paper presents simulation results under steady condition. In a real engine application, the turbine will undergo unsteady flow condition of EGR exhaust gas. In future work, the comparison can be made for both asymmetric and symmetric turbines in unsteady conditions to match real applications.

\section{Acknowledgement}

Our appreciation goes to Dr Uswah Khairuddin of Universiti Teknologi Malaysia for her contribution through her project grant Reduction of damper-hunting to duct pulsation in high-speed VAV system (R.K130000.7343.4B370).

\section{References}

[1] Hebbar, Gurumoorthy, and Anant Krishna Bhat. "Investigations on Performance and Emissions of a Stationary DI Diesel Engine with Different Exhaust Gas Recirculation Temperatures/Farklı Egzoz Gazı Devir Daim Sıcaklıkları ile Yerleşik Bir Dizel Motorun Emisyon ve Performans Üzerine Araştırmalar." International Journal of Automotive Engineering and Technologies 2, no. 1 (2013): 1-9.

[2] Levendis, Yiannis A., Iraklis Pavlatos, and Richard F. Abrams. Control of diesel soot, hydrocarbon and NOx emissions with a particulate trap and EGR. No. 940460. SAE Technical Paper, 1994. https://doi.org/10.4271/940460

[3] Srinath Pai, Amriya Tasneem H.R., Shivaraju N, Dr. Sreeprakash. "The study of EGR Effect on Diesel Engine Performance and Emission." In International Conference, ICEITSW, Institute of Engineering and Technology, 2013.

[4] Hoseini, Seyed Salar, Gholamhassan Najafi, and Barat Ghobadian. "Thermal and fluid simulation of a new diesel engine cooling exhaust gas recirculation system to reduce exhaust gas emissions." Journal of Advanced Research in Fluid Mechanics and Thermal Sciences 51, no. 2 (2018): 197-208.

[5] Zala, Mukesh Rameshbhai. "Optimization of EGR rate on multi cylinders 4-stroke diesel engine." International Journal of Engineering Research \& Technology 1, no. 4 (2012).

[6] Müller, Markus, Thomas Streule, Siegfried Sumser, Gernot Hertweck, Arno Nolte, and Wolfram Schmid. "The asymmetric twin scroll turbine for exhaust gas turbochargers." In Turbo Expo: Power for Land, Sea, and Air, vol. 43161, pp. 1547-1554. 2008. https://doi.org/10.1115/GT2008-50614

[7] Mizumachi, Nagao. "A study on performance of radial turbine under unsteady flow conditions." Report of the institute of industrial science, The University of Tokyo 28, no. 1 (1979).

[8] Benson, R. S., and A. Whitfield. "An experimental investigation of the non-steady flow characteristics of a centrifugal compressor." Proceedings of the Institution of Mechanical Engineers 180, no. 1 (1965): 641-672. https://doi.org/10.1243/PIME PROC $1965 \quad 180043 \quad 02$ 
[9] Wallace, F. J., and G. P. Blair. The pulsating-flow performance of inward radial-flow turbines. Vol. 79900. American Society of Mechanical Engineers, 1965.

https://doi.org/10.1115/65-GTP-21

[10] Newton, Peter. "An experimental and computational study of pulsating flow within a double entry turbine with different nozzle settings." PhD thesis, Imperial College London, 2013. https://doi.org/10.1115/GT2014-26151

[11] Copeland, Colin D. "Evaluation of steady and pulsating flow performance of a double-entry turbocharger turbine." PhD Thesis, Imperial College of London, 2009.

[12] Copeland, Colin D., Ricardo Martinez-Botas, and Martin Seiler. "Unsteady performance of a double entry turbocharger turbine with a comparison to steady flow conditions." Journal of turbomachinery 134, no. 2 (2012). https://doi.org/10.1115/1.4003171

[13] Copeland, Colin D., Ricardo Martinez-Botas, and Martin Seiler. "Comparison between steady and unsteady doubleentry turbine performance using the quasi-steady assumption." Journal of Turbomachinery 133, no. 3 (2011). https://doi.org/10.1115/1.4000580

[14] Copeland, Colin D., Peter J. Newton, Ricardo Martinez-Botas, and Martin Seiler. "The effect of unequal admission on the performance and loss generation in a double-entry turbocharger turbine." Journal of Turbomachinery 134, no. 2 (2012). https://doi.org/10.1115/1.4003226

[15] Karamanis, N., R. F. Martinez-Botas, and C. C. Su. "Detailed Flow Measurements at the Exit of a Mixed Flow Turbine Under Steady Flow Conditions." In Turbo Expo: Power for Land, Sea, and Air, vol. 78583, p. V001T03A054. American Society of Mechanical Engineers, 1999. https://doi.org/10.1115/99-GT-342

[16] Martinez-Botas, Ricardo, and Masakazu Sakai. "Asymmetric double-entry turbine." U.S. Patent 9,845,770, issued December 19, 2017.

[17] Gurunathan, Balamurugan A. "Experimental evaluation of steady and pulsating flow performance of an asymmetric double entry turbine for an automotive turbocharger." PhD Thesis, Imperial College London, 2016.

[18] Abidat, Miloud. "Design and testing of a highly loaded mixed flow turbine." PhD diss., University of London, 1991.

[19] Banisoleiman, Kian. 11th International Conference on Turbochargers and Turbocharging: 13-14 May 2014: 13-14 May 2014. Vol. 1384. Elsevier, 2014.

[20] Palfreyman, D., and R. F. Martinez-Botas. "The pulsating flow field in a mixed flow turbocharger turbine: An experimental and computational study." Journal of Turbomachinery. 127, no. 1 (2005): 144-155. https://doi.org/10.1115/1.1812322

[21] D. Japikse, N. C. Baines. "Introduction to Turbomachinery Concepts, ETI." 1997. 